\title{
Transmittance measurements in non-alternating magnetic field as reliable method for determining of heating properties of Fe304 magnetic nanoparticles
}

\section{Magdalena Radović}

VINCA Institute of Nuclear Sciences: Univerzitet u Beogradu Institut za nuklearne nauke Vinca

Marija Mirković

VINCA Institute of Nuclear Sciences: Univerzitet u Beogradu Institut za nuklearne nauke Vinca

\section{Aleksandar S. Nikolić}

VINCA Institute of Nuclear Sciences: Univerzitet u Beogradu Institut za nuklearne nauke Vinca

\section{Milorad Kuraica}

VINCA Institute of Nuclear Sciences: Univerzitet u Beogradu Institut za nuklearne nauke Vinca

\section{Predrag Iskrenović}

VINCA Institute of Nuclear Sciences: Univerzitet u Beogradu Institut za nuklearne nauke Vinca

\section{Zorana Milanović}

VINCA Institute of Nuclear Sciences: Univerzitet u Beogradu Institut za nuklearne nauke Vinca

\section{Sanja Vranješ-Đurić}

VINCA Institute of Nuclear Sciences: Univerzitet u Beogradu Institut za nuklearne nauke Vinca

Marko Peric ( $\nabla$ markoperic1983@gmail.com )

VINCA Institute of Nuclear Sciences: Univerzitet u Beogradu Institut za nuklearne nauke Vinca

\section{Research Article}

Keywords: Magnetic nanoparticles, hyperthermia, laser transmittance, non-alternating magnetic field, 177Lu labeling

Posted Date: April 26th, 2021

DOI: https://doi.org/10.21203/rs.3.rs-458080/v1

License: (c) (i) This work is licensed under a Creative Commons Attribution 4.0 International License. Read Full License 


\section{Abstract}

Different phosphates and phosphonates have shown excellent coating ability toward magnetic nanoparticles, improving their stability and biocompatibility which enables their biomedical application. The magnetic hyperthermia efficiency of phosphates (IDP and IHP) and phosphonates (MDP and HEDP) coated $\mathrm{Fe}_{3} \mathrm{O}_{4}$ magnetic nanoparticles (MNPs) were evaluated in an alternating magnetic field. For a deeper understanding of hyperthermia, the behavior of investigated MNPs in the non-alternating magnetic field was monitored by measuring the transparency of the sample. To investigate their theranostic potential coated $\mathrm{Fe}_{3} \mathrm{O}_{4}$-MNPs were radiolabeled with radionuclide ${ }^{177} \mathrm{Lu}$. Phosphate coated MNPs were radiolabeled in high radiolabeling yield (>99\%) while phosphonate coated MNPs reached maximum radiolabeling yield of $78 \%$. Regardless lower radiolabeling yield both radiolabeled phosphonate MNPs may be further purified reaching radiochemical purity of more than $95 \%$. In vitro stabile radiolabeled nanoparticles in saline and HSA were obtained. The high heating ability of phosphates and phosphonates coated MNPs as sine qua non for efficient in vivo hyperthermia treatment and satisfactory radiolabeling yield justifies their further research in order to develop new theranostic agents.

\section{Introduction}

In the past few decades magnetic nanoparticles (MNPs) have attracted far-reaching attention due to the expeditiously growing possibilities for their applications such as nanomaterial-based catalysis, biomedicine and tissue specific targeting, magnetic resonance imaging, magnetic particle imaging, data storage, environmental remediation, etc. [1, 2]. Due to their extraordinary physico-chemical qualities, MNPs are especially used in the biomedicine. The MNPs may be similar to cell, virus, protein or gene size, but also they can easily enter a variety of cell structures. The heating of MNPs by changing the orientation of their magnetic domains in an alternating external magnetic field is substantial for various medical applications such as hyperthermia and triggered drug delivery to the targeted region of the body by induced self-heating [3,4]. However, surface functionalization of MNPs is pivotal for the fruitful application in medicine. Coating of MNPs increases the colloidal stability, prevents aggregation and agglomeration of the particles and provides nontoxicity in physiological conditions. It is noteworthy that phosphates and phosphonates are water soluble and biocompatible and allow convenient stability and reduced cytotoxicity of MNPs for medical application [5]. Furthermore, they have a large binding affinity to the bone tissue which allows application in various medical conditions such as osteoporosis and bone tumors [6, 7]. In addition, phosphates and phosphonates are higly efficient chelators. Bisphosphonatebased coordination complexes with ${ }^{99 \mathrm{~m}} \mathrm{Tc}$ have been widely used for bone scintigraphy, due to their high sensitivity, specificity, and accuracy for detecting skeletal metastatic diseases [8] The binding of phosphates and phosphonates to the surface of MNPs and labeling with different radionuclides make them appropriate for combined radionuclide-hyperthermia therapy or SPECT/PET-MRI diagnostics [5, 9]. ${ }^{177} \mathrm{Lu}$ has become favored in recent years in the therapy of neuroendocrine and prostate tumors, due to very suitable physicochemical characteristics $\left(T_{1 / 2}=6.7\right.$ days, $\mathrm{E}_{\beta \max }$ of $\left.497 \mathrm{keV}(78.6 \%)\right)$ [10]. An 
additional advantage of using ${ }^{177} \mathrm{Lu}$ is $\mathrm{\gamma}$-ray emission $\left(\mathrm{E}_{\mathrm{\gamma}}\right.$ of $208 \mathrm{keV}(11 \%)$ and $\left.113 \mathrm{keV}(6.6 \%)\right)$ during its decay which allows the monitoring of therapy. There are a small number of studies that refer to the potential use of ${ }^{177}$ Lu labeled MNPs in cancer radionuclide therapy [11].

In the present study heating capacity of $\mathrm{Fe}_{3} \mathrm{O}_{4}$ based MNPs coated with inositol hexaphosphate (IHP), imidodiphosphate (IDP), hydroxyethylidene diphosphonic acid (HEDP), and methanediylbis(phosphonic acid) (MDP) has been investigated for possible hyperthermia treatment. In order to analyze and explain the heating capacity of synthesized samples minutely, we monitored the behavior of MNPs in a nonalternating magnetic field by measuring laser transparency and correlated obtained data with hyperthermia measurements. Further, phosphate and phosphonate functionalized MNPs were labeleled with ${ }^{177}$ Lu with the aim to investigate their potential for use in diagnosis or hyperthermia cancer therapy.

\section{Experimental}

Methylene diphosphonate (medronic acid, MDP), 1-hydroxyethane-1,1-diphosphonate (etidronic acid, HEDP), imidodiphosphate tetrasodium salt (IDP), inositol hexaphosphoric acid sodium salt (IHP), iron (III) chloride hexahydrate $\left(\mathrm{FeCl}_{3} \otimes 6 \mathrm{H}_{2} \mathrm{O}\right)$, iron (II) sulfate heptahydrate $\left(\mathrm{FeSO}_{4} \otimes 7 \mathrm{H}_{2} \mathrm{O}\right)$ and aqueous ammonia solution $(25 \% \mathrm{w} / \mathrm{w})$ were purchased from Sigma-Aldrich and were analytical grade reagents used without further purification. The human serum was obtained from the National Blood Transfusion Institute (Belgrade, Serbia). Water used in all experiments was purified using the Milli-Q system (Millipore Co., Billerica, MA, USA). Lutetium-177 was obtained from Polatom, Poland (in the form of ${ }^{177} \mathrm{LuCl}_{3}$, specific activity $>500 \mathrm{GBq} / \mathrm{mg} \mathrm{Lu}$ ).

Synthesis and characterization of $\mathrm{Fe}_{3} \mathrm{O}_{4}-\mathrm{MDP}, \mathrm{Fe}_{3} \mathrm{O}_{4}-\mathrm{HEDP}, \mathrm{Fe}_{3} \mathrm{O}_{4}-\mathrm{IDP}$, and $\mathrm{Fe}_{3} \mathrm{O}_{4}-\mathrm{IHP}$ MNPs were previously reported $[12,13]$. Briefly, after synthesis of $\mathrm{Fe}_{3} \mathrm{O}_{4} \mathrm{MNPs}$ by coprecipitation method, a water solution of phosphate or phosphonate ligand (MDP, HEDP, IDP, IHP) at the ratio $\mathrm{Fe}_{3} \mathrm{O}_{4}$ :coating ligand $=1: 1$ was added, and the functionalization reaction was carried out overnight at room temperature. The excess of unreacted coating ligand was eliminated by dialysis against deionized water for one day. The magnetic hyperthermia efficiency of $\mathrm{Fe}_{3} \mathrm{O}_{4}-\mathrm{MPD}, \mathrm{Fe}_{3} \mathrm{O}_{4}$-HEDP, $\mathrm{Fe}_{3} \mathrm{O}_{4}$-IDP, and $\mathrm{Fe}_{3} \mathrm{O}_{4}$-IHP MNPs was analyzed by using Commercial AC applicator (model DM100, nB nanoscale Biomagnetics). The heat generation under alternating magnetic field $(30 \mathrm{mT})$ and the resonant frequency of $397 \mathrm{kHz}$ was measured directly on the samples dispersed in water. The heating ability of MNPs $(2 \mathrm{mg} / \mathrm{ml})$, defined as specific power absorption (SPA), calculated according to the following formula: SPA $=\left(\mathrm{C}_{\mathrm{p}} \cdot \mathrm{m}_{\mathrm{w}} / \mathrm{m}_{\mathrm{m}}\right) \cdot(\Delta \mathrm{T} /$ $\Delta t$ ), where $C p$ is the specific heat capacity of the medium $\left(C_{p} \sim C_{\text {water }}=4.18 \mathrm{Jg}^{-1} \mathrm{~K}^{-1}\right), \mathrm{m}_{\mathrm{w}}$ and $\mathrm{m}_{\mathrm{m}}$ are the masses of the medium (water) and the magnetic nanoparticles, and $\Delta T / \Delta t$ is the initial slope of the time dependent temperature curve [14].

For the analysis of the sample in non-alternating external MF, device shaped in our laboratory was used [15]. Sanyo laser diode DL5147-040 in the single mode regime at wavelength $\lambda=655 \mathrm{~nm}$ was applied. Transmitted laser light was measured with a photodiode. 


\section{Labeling of coated MNPs with ${ }^{177} \mathrm{Lu}$}

${ }^{177}$ Lu-labeling of phosphates and phosphonates coated $\mathrm{Fe}_{3} \mathrm{O}_{4}$ MNPs was obtained using the method previously described $[11,16]$. Briefly, ${ }^{177} \mathrm{LuCl}_{3}$ solution (approximately $185 \mathrm{MBq}$ in $5 \mu \mathrm{l}$ ) was added to an aqueous suspension of coated $\mathrm{Fe}_{3} \mathrm{O}_{4} \mathrm{MNPs}(5 \mathrm{mg} / \mathrm{ml}$ at pH 4.5) and incubated at room temperature with continual stirring for $1 \mathrm{~h}$. To quantify the radiolabeling yield of ${ }^{177} \mathrm{Lu}$-labeled MNPs and their radiochemical purity after purification by magnetic decantation, ITLC was performed on SG sheets with $0.1 \mathrm{M}$ acetate buffer as the mobile phase. In this system, ${ }^{177} \mathrm{Lu}$-labeled MNPs remained at the origin ( $\mathrm{Rf}=$ $0.0-0.1)$, while the unbound ${ }^{177} \mathrm{Lu}^{3+}$ migrated with the solvent front $(\mathrm{Rf}=0.8-0.9)$.

\section{In vitro stability of ${ }^{177}$ Lu-MNPs}

The in vitro stability of purified ${ }^{177}$ Lu-coated MNPs was determined in saline or human serum solution (total volume of $2 \mathrm{ml}$ ) by measuring the free, unbound ${ }^{177} \mathrm{Lu}$ in relation to the ${ }^{177}$ Lu-labeled coated MNPs (bound ${ }^{177} \mathrm{Lu}$ ) during incubation at $37^{\circ} \mathrm{C}$ for $96 \mathrm{~h}$. Small amounts of sample $(50 \mu \mathrm{l})$ were taken at different time points $(1,24,48$, and $96 \mathrm{~h}$ ) and analyzed by ITLC (SG plates) using $0.1 \mathrm{M}$ acetate buffer as the mobile phase.

\section{Results And Discussion}

In order to apply magnetic hyperthermia, it is necessary to take into account physiological limitations. Due to the eddy currents, MFs of high frequencies can cause local heating also in the sections of the tissue where no magnetic particles have been found. Along with clinical restrictions, technical issues should be also taken into account, since most studies on biological samples encompass a tight frequency range. The applied frequencies, together with the amplitude of the alternating field, are mainly based on literature data $[17,18]$. The temperature increase of $\mathrm{Fe}_{3} \mathrm{O}_{4}-\mathrm{MPD}, \mathrm{Fe}_{3} \mathrm{O}_{4}-\mathrm{HEDP}, \mathrm{Fe}_{3} \mathrm{O}_{4}-\mathrm{IDP}$, and $\mathrm{Fe}_{3} \mathrm{O}_{4}-\mathrm{IHP} \mathrm{MNPs}(5 \mathrm{mg} / \mathrm{ml})$ as a function of the time was evaluated under a frequency of $397 \mathrm{kHz}$ and magnetic field strength of $30 \mathrm{mT}$ (Fig. 1).

Although all specimens under investigation have shown substantial heating capacity, it is obvious that $\mathrm{Fe}_{3} \mathrm{O}_{4}$-HEDP MNPs achieved the highest temperature values. In order to explain obtained trends, we employed the analysis of MNPs behavior in a non-alternating magnetic field, by measuring laser transmittance [19-23]. Previously this method gave satisfactory valuable data [15, 24]. The analysis was carried out at $30 \mathrm{mT}$ and $400 \mathrm{mT}$ and the results are depicted in Fig. 2. At the beginning of the measuring, the MF is switched off, and the specimens showed initial transparency. By employing the MF, the transparency of the samples abruptly decreases. The magnitude of this decrease depends on the specimen's type and field strength. Regardless of the field used $\mathrm{Fe}_{3} \mathrm{O}_{4}-\mathrm{MPD}$ and $\mathrm{Fe}_{3} \mathrm{O}_{4}-\mathrm{HEDP}$ MNPs showed a lesser decline of transparency in comparison to $\mathrm{Fe}_{3} \mathrm{O}_{4}-\mathrm{IHP}$ and $\mathrm{Fe}_{3} \mathrm{O}_{4}-\mathrm{IDP}$ MNPs. After some time (app $60 \mathrm{~s}$ ) sudden increase of relative transmittance has been observed, due to the zippering of magnetic chains. It is noteworthy that external MF arranges MNPs along the field lines, like miniature 
magnetic needles [15, 20,23]. Such ordering of magnetic domains causes strong mutual attraction and subsequent formation of magnetic chains. In addition, the magnetic chains are arranged in space thereby building a quasi-lattice made of parallel lined magnetic threads. The source of laser is positioned in such a manner that light propagates through the quasi-lattice parallel with lines of non-alternating MF. Contrary to the case when nanoparticles are chaotically distributed, magnetic chains encounter a much lesser number of scattering centers. In other words, the quasi-lattice possesses far smaller cross section for scattering compared to randomly distributed particles $[15,20,23]$. As a consequence, the intensity of the transmitted light rises. The slope of the increase is very steep when the field of $400 \mathrm{mT}$ was employed, whereas for the lower fields the increase is gradual. Previous study has shown that depth and width of the well depend on MF strength and kind of ferrofluid sample [15, 25]. Comparing the results from Figs. 1 and 2 it is obvious that the heating capacity of the sample (Fig. 1.) stands in correlation with depth and width of the well (Fig. 2.). The specimens displaying the highest heating capacity in alternating $\mathrm{MF}, \mathrm{Fe}_{3} \mathrm{O}_{4}-\mathrm{MPD}$, and $\mathrm{Fe}_{3} \mathrm{O}_{4}$-HEDP MNPs, also show the shallower and narrower wells in non-alternating MF. $\mathrm{Fe}_{3} \mathrm{O}_{4}$-MPD and $\mathrm{Fe}_{3} \mathrm{O}_{4}$-HEDP MNPs reach again the initial transparency in the shorter time interval in comparison to $\mathrm{Fe}_{3} \mathrm{O}_{4}-\mathrm{IHP}$ and $\mathrm{Fe}_{3} \mathrm{O}_{4}$-IDP MNPs. By employing the field of $30 \mathrm{mT} \mathrm{Fe}_{3} \mathrm{O}_{4}-\mathrm{IHP}$ and $\mathrm{Fe}_{3} \mathrm{O}_{4^{-}}$ IDP MNPs have not reached the initial transparency even after $300 \mathrm{~s}$. Furthermore at the point of saturation $\mathrm{Fe}_{3} \mathrm{O}_{4}-\mathrm{MPD}$ and $\mathrm{Fe}_{3} \mathrm{O}_{4}$-HEDP MNPs showed significantly higher values of transparency.

By comparing the amount of precipitate formed in the time regime when the field was operative (Fig. 3 . samples 1b, 2b, 3b, 4b) and also at the saturation point (Fig. 3, samples1c, 2c, 3c, 4c) it can be observed that the highest precipitation occurs in the case of $\mathrm{Fe}_{3} \mathrm{O}_{4}-\mathrm{MDP}$ and $\mathrm{Fe}_{3} \mathrm{O}_{4}-\mathrm{HEDP}$ MNPs. $\mathrm{Fe}_{3} \mathrm{O}_{4}-\mathrm{IDP}$ and $\mathrm{Fe}_{3} \mathrm{O}_{4}$-IHP MNPs samples have shown less tendency to precipitate, which has been noted by the amount of precipitate at saturation point.

In addition to the practiced MF strength and frequency, other factors such as particle size and shape along with the concentration of the sample significantly influence the behavior of MNPs in nonalternating and alternating MF [26]. Generally, more concentrated dispersions of MNPs broaden the application, therefore various electric and magnetic fields can be used. By diminishing the concentration of the sample, SPA values decline, and below $2 \mathrm{mg} / \mathrm{ml}$ heating effect could not be detected (Fig. 4.)

The behavior of $\mathrm{Fe}_{3} \mathrm{O}_{4}$-HEDP MNPs in non-alternating MF $(400 \mathrm{mT})$ for different concentrations is depicted in Fig. 5.

The field of $400 \mathrm{mT}$ has been used in order to compare the well depth at different concentrations of $\mathrm{Fe}_{3} \mathrm{O}_{4}$-HEDP MNPs, since at $30 \mathrm{mT}$ the wells are not distinct, and effect is very poor. At the highest tested concentration $(8 \mathrm{mg} / \mathrm{ml})$ the initial transparency, when the MF is switched off, is the lowest. By decreasing the concentration the initial transparency of the sample rises. The depth of the well increases with the dilution until the concentration of $1 \mathrm{mg} / \mathrm{ml}$. This concentration for this particular sample is turning point, from which the decrease of the well depth starts (the effect is getting weaker). At the lowest concentrations $(0.1$ and $0.2 \mathrm{mg} / \mathrm{ml})$, the well could not be observed and the increase of transparency is very small reaching only the initial value (when the MF was switched-off). Observations are in correlation 
with hyperthermia studies, i.e. the SPA values decrease with a dilution of the sample till the concentration of $1 \mathrm{mg} / \mathrm{ml}$, when the loss of heating capacity has been observed (Fig. 4.). Since the shape of the well depends on the magnetic properties and the applied concentration of the sample, by finding a turning point with a sharp decrease in the depth of the well, it is possible to detect the concentration at which there is a loss of heating capacity.

\section{Radiolabeling and in vitro stability of ${ }^{177}$ Lu-MNPs}

The aim was to optimize the ${ }^{177}$ Lu radiolabeling of coated MNPs toward their further in vivo applications. ${ }^{177} \mathrm{Lu}$ as trivalent metal usually easily make complexes at room temperature with MNPs that possess available phosphates and phosphonates functional groups on the surface. The radiolabeling yield of ${ }^{177}$ Lu-MNPs as well as their radiochemical purity after purification by magnetic decantation was determined using ITLC-SG chromatography with $0.1 \mathrm{M}$ acetate buffer as the mobile phase (Table 1). Radiolabeling yield after 30 min of reaction time was over $99 \%$ for ${ }^{177}$ Lu-IDP-MNPs and ${ }^{177}$ Lu-IHP-MNPs while the radiolabelling yield of ${ }^{177}$ Lu-MDP-MNPs and ${ }^{177}$ Lu-HEDP-MNPs was $78.7 \pm 0.7 \%$ and $75.0 \pm$ $1.1 \%$ respectively. Both radiolabeled phosphonate-coated MNPs can be further purified from free ${ }^{177} \mathrm{Lu}$ using magnetic purification reaching radiochemical purity of over $95 \%$. The in vitro stability of ${ }^{177} \mathrm{Lu}$ MNPs was tested by examining their radiochemical purity at different time intervals after storage of the samples at $37^{\circ} \mathrm{C}$ in saline and human serum up to $96 \mathrm{~h}$. In vitro stability of ${ }^{177}$ Lu-MNPs is shown in Fig. 6. ${ }^{177} \mathrm{Lu}$-IDP-MNPs and ${ }^{177} \mathrm{Lu}-\mathrm{IHP}-\mathrm{MNPs}$ were quite stable, showing the minimal release of ${ }^{177} \mathrm{Lu}$ after $96 \mathrm{~h}$, confirming the strong metal binding to $\mathrm{Fe}_{3} \mathrm{O}_{4}-\mathrm{IDP}$ and $\mathrm{Fe}_{3} \mathrm{O}_{4}-\mathrm{IHP}$ MNPs. ${ }^{177}$ Lu-MDP-MNPs and ${ }^{177}$ Lu-HEDP-MNPs show about $10 \%$ of released ${ }^{177}$ Lu after $96 \mathrm{~h}$ indicating their less desirable in vivo behavior in relation to phosphate-coated MNPs.

Table 1

Radiolabeling yield and radiochemical purity of ${ }^{177}$ Lu-MNPs after magnetic decantation

\begin{tabular}{|lll|}
\hline $\begin{array}{l}\text { 177Lu-MNPs } \\
\text { (\%) }\end{array}$ & $\begin{array}{l}\text { Radiolabeling yield } \\
\text { 177 Lu-MDP- }\end{array}$ & $\begin{array}{l}\text { Radiochemical purity after purification using magnetic } \\
\text { decantation (\%) }\end{array}$ \\
\hline $\begin{array}{l}\text { MNPs } \\
\text { MN7 Lu-HEDP- }\end{array}$ & $78.7 \pm 0.7$ & $95.4 \pm 0.5$ \\
$\begin{array}{l}\text { MNPS } \\
\text { MNP-IDP- }\end{array}$ & $99.1 \pm 1.3$ & $95.9 \pm 0.6$ \\
$\begin{array}{l}\text { 177 Lu-IHP- } \\
\text { MNPs }\end{array}$ & $99.0 \pm 0.9$ & $99.9 \pm 1.2$ \\
\hline
\end{tabular}

\section{Conclusion}


In this paper the behavior of $\mathrm{Fe}_{3} \mathrm{O}_{4}-\mathrm{MDP}, \mathrm{Fe}_{3} \mathrm{O}_{4}-\mathrm{HEDP}, \mathrm{Fe}_{3} \mathrm{O}_{4}-\mathrm{IDP}$, and $\mathrm{Fe}_{3} \mathrm{O}_{4}-\mathrm{IHP}$ MNPs in alternating and non-alternating external magnetic fields were analyzed. The interaction of MNPs with the external alternating magnetic field is of exceptional interest due to their potential application in magnetic hyperthermia therapy. The results given, point out that the MDP, HEDP, IDP, and IHP-coated MNPs could achieve significant heating capacity at $397 \mathrm{kHz}$ and $30 \mathrm{mT}$ frequencies and thus show potential for biomedical applications. In addition, for more comprehensive understanding of hyperthermia, the interaction of $\mathrm{Fe}_{3} \mathrm{O}_{4}-\mathrm{MDP}, \mathrm{Fe}_{3} \mathrm{O}_{4}-\mathrm{HEDP}, \mathrm{Fe}_{3} \mathrm{O}_{4}-$ IDP, and $\mathrm{Fe}_{3} \mathrm{O}_{4}-\mathrm{IHP}$ MNPs with non-alternating magnetic field was explored. The behavior of MNPs has been monitored by continual measuring of laser transmittance of the sample before turning on non-alternating magnetic field, in the course of time when the field is operational and when the field was turned off. The obtained curves point out that $\mathrm{Fe}_{3} \mathrm{O}_{4}-\mathrm{MDP}$ and $\mathrm{Fe}_{3} \mathrm{O}_{4}$-HEDP MNPs have higher magnetic activity than $\mathrm{Fe}_{3} \mathrm{O}_{4}-\mathrm{IDP}$ and $\mathrm{Fe}_{3} \mathrm{O}_{4}-\mathrm{IHP}$ MNPs, which is in accordance with hyperthermia measurements.

The dilution of the sample leads to a lowering of heating capacity. This process has been tracked by measuring of SPA values, and laser transmittance in a non-alternating field. Within the range of $8-2$ $\mathrm{mg} / \mathrm{cm}^{3}$, minor changes in SPA values have been observed. However, the transparency measurement represents a far more precise method. Hence, the measurements in the non-alternating MF for the same concentration range have shown significant changes in magnetic behavior. Below $2 \mathrm{mg} / \mathrm{cm}^{3}$ heating effect could not be noticed. Additionally, substantial changes in the curve profile (Fig. 5.) have been recorded below the concentration of $2 \mathrm{mg} / \mathrm{cm}^{3}$.

After the analysis of the heating capacity of phosphates and phosphonates coated MNPs, method for their labeling with ${ }^{177}$ Lu was successfully developed in order to produce radiolabeled nanoagent with high radiochemical purity and in vitro stability as the necessary requirements for in vivo use. Future studies will focus on the investigation of the possible potential of ${ }^{177}$ Lu-MNPs as theranostic agents, for diagnostic imaging and therapeutic hyperthermia as well.

\section{Declarations}

\section{Conflicts of interest statement}

No potential conflict of interest was reported by the authors.

\section{Availability of data and material}

The data that support the findings of this study are available on request from the corresponding author.

\section{Funding}

The research was supported by the Ministry of Education, Science and Technological Development of the Republic of Serbia (contract numbers 451-03-9/2021-14/200017, 451-03-9/2021-14/ 200168, 451-0368/2020-14) and through funding the VINCENT Center of Excellence. 


\section{References}

[1] C.C. Berry, A.S.G. Curtis, Functionalisation of magnetic nanoparticles for applications in biomedicine, J. Phys. D Appl. Phys. 36 (2003) 198-206.

[2] 0. V. Salata, Applications of nanoparticles in biology and medicine, J. Nanobiotechnology. 2 (2004) 3. doi:10.1186/1477-3155-2-3.

[3] H. Mamiya, B. Jeyadevan, Hyperthermic effects of dissipative structures of magnetic nanoparticles in large alternating magnetic fields, Sci. Rep. 1 (2011). doi:10.1038/srep00157.

[4] H. Zolata, H. Afarideh, F.A. Davani, Triple Therapy of HER2+ Cancer Using Radiolabeled Multifunctional Iron Oxide Nanoparticles and Alternating Magnetic Field, Cancer Biother. Radiopharm. 31 (2016) 324329. doi:10.1089/cbr.2016.2068.

[5] M.-A. Karageorgou, S. Vranješ-Djurić, M. Radović, A. Lyberopoulou, B. Antić, M. Rouchota, M. Gazouli, G. Loudos, S. Xanthopoulos, Z. Sideratou, D. Stamopoulos, P. Bouziotis, Gallium-68 Labeled Iron Oxide Nanoparticles Coated with 2,3-Dicarboxypropane-1,1-diphosphonic Acid as a Potential PET/MR Imaging Agent: A Proof-of-Concept Study., Contrast Media Mol. Imaging. 2017 (2017) 6951240-6951253. doi:10.1155/2017/6951240.

[6] J. Gałęzowska, Interactions between Clinically Used Bisphosphonates and Bone Mineral: from Coordination Chemistry to Biomedical Applications and Beyond, ChemMedChem. 13 (2018) 289-302. doi:10.1002/cmdc.201700769.

[7] M. Mirković, Z. Milanović, D. Stanković, Đ. Petrović, S. Vranješ-Đurić, D. Janković, M. Radović, Investigation of ${ }^{177}$ Lu-labeled HEDP, DPD, and IDP as potential bone pain palliation agents, J. Radiat. Res. Appl. Sci. 13 (2020) 27-36. doi:10.1080/16878507.2019.1702243.

[8] M. Vorne, S. Vähätalo, T. Lantto, A clinical comparison of 99mTc-DPD and two 99mTc-MDP agents, Eur. J. Nucl. Med. 8 (1983) 395-397. doi:10.1007/BF00253214.

[9] S. Same, A. Aghanejad, S. Akbari Nakhjavani, J. Barar, Y. Omidi, Radiolabeled theranostics: magnetic and gold nanoparticles., Bioimpacts. 6 (2016) 169-181. doi:10.15171/bi.2016.23.

[10] S. Banerjee, M.R.A. Pillai, F.F. (Russ) Knapp, Lutetium-177 Therapeutic Radiopharmaceuticals: Linking Chemistry, Radiochemistry, and Practical Applications, Chem. Rev. 115 (2015) 2934-2974. doi:10.1021/cr500171e.

[11] M. Ognjanović, M. Radović, M. Mirković, Ž. Prijović, M. Del Puerto Morales, M. Čeh, S. Vranješ-Durić, B. Antić, 99mTc-, 90Y-, and 177Lu-Labeled Iron Oxide Nanoflowers Designed for Potential Use in Dual Magnetic Hyperthermia/Radionuclide Cancer Therapy and Diagnosis, ACS Appl. Mater. Interfaces. 11 (2019) 41109-41117. doi:10.1021/acsami.9b16428. 
[12] M. Mirković, M. Radović, D. Stanković, Z. Milanović, D. Janković, M. Matović, M. Jeremić, B. Antić, S. Vranješ-Đurić, $99 \mathrm{mTc}$-bisphosphonate-coated magnetic nanoparticles as potential theranostic nanoagent, Mater. Sci. Eng. C. 102 (2019) 124-133. doi:10.1016/j.msec.2019.04.034.

[13] M. Radović, M. Mirković, M. Perić, D. Janković, A. Vukadinović, D. Stanković, D. Petrović, M. Bošković, B. Antić, M. Marković, S. Vranješ-Durić, Design and preparation of $90 Y$-labeled imidodiphosphate- and inositol hexaphosphate-coated magnetic nanoparticles for possible medical applications, J. Mater. Chem. B. 5 (2017) 8738-8747. doi:10.1039/c7tb02075a.

[14] P.B. Shete, R.M. Patil, N.D. Thorat, A. Prasad, R.S. Ningthoujam, S.J. Ghosh, S.H. Pawar, Magnetic chitosan nanocomposite for hyperthermia therapy application: Preparation, characterization and in vitro experiments, Appl. Surf. Sci. 288 (2014) 149-157. doi:10.1016/J.APSUSC.2013.09.169.

[15] M.M. Kuraica, P. Iskrenović, M. Perić, I. Krstić, A.S. Nikolić, External magnetic field influence on magnetite and cobalt-ferrite nano-particles in ferrofluid, Chem. Pap. 72 (2018) 1535-1542. doi:10.1007/s11696-017-0380-8.

[16] M. Mirković, Z. Milanović, D. Stanković, Đ. Petrović, S. Vranješ-Đurić, D. Janković, M. Radović, Investigation of 177Lu-labeled HEDP, DPD, and IDP as potential bone pain palliation agents, J. Radiat. Res. Appl. Sci. 13 (2020) 27-36. doi:10.1080/16878507.2019.1702243.

[17] W.J. Atkinson, I.A. Brezovich, D.P. Chakraborty, Usable Frequencies in Hyperthermia with Thermal Seeds, IEEE Trans. Biomed. Eng. 31 (1984) 70-75. doi:10.1109/TBME.1984.325372.

[18] I. Brezovich, Low frequency hyperthermia: capacitive and ferromagnetic thermoseed methods, Med. Phys. Monogr. 16 (1988) 82-111.

[19] J. Li, X.D. Liu, Y.Q. Lin, Y. Huang, L. Bai, Relaxation behavior measuring of transmitted light through ferrofluids film, Appl. Phys. B Lasers Opt. 82 (2006) 81-84. doi:10.1007/s00340-005-2045-5.

[20] J.M. Laskar, J. Philip, B. Raj, Light scattering in a magnetically polarizable nanoparticle suspension, Phys. Rev. E - Stat. Nonlinear, Soft Matter Phys. 78 (2008). doi:10.1103/PhysRevE.78.031404.

[21] J. Philip, J.M. Laskar, Optical Properties and Applications of Ferrofluids-A Review, J. Nanofluids. 1 (2013) 3-20. doi:10.1166/jon.2012.1002.

[22] S. Brojabasi, T. Muthukumaran, J.M. Laskar, J. Philip, The effect of suspended Fe304 nanoparticle size on magneto-optical properties of ferrofluids, Opt. Commun. 336 (2015) 278-285. doi:10.1016/j.optcom.2014.09.065.

[23] S. Brojabasi, B.B. Lahiri, J. Philip, External magnetic field dependent light transmission and scattered speckle pattern in a magnetically polarizable oil-in-water nanoemulsion, Phys. B Condens. Matter. 454 (2014) 272-278. doi:10.1016/j.physb.2014.08.003. 
[24] M. Perić, M. Radović, M. Mirković, A.S. Nikolić, P. Iskrenović, D. Janković, S. Vranješ-Đurić, The analysis of 2,3-dicarboxypropane-1,1-diphosphonic acid-coated magnetite nanoparticles under an external magnetic field and their radiolabeling for possible theranostic applications, New J. Chem. 43 (2019) 5932-5939. doi:10.1039/c8nj06478d.

[25] M. Lakić, L. Andjelković, M. Šuljagić, P. Vulić, M. Perić, P. Iskrenović, I. Krstić, M.M. Kuraica, A.S. Nikolić, Optical evidence of magnetic field-induced ferrofluid aggregation: Comparison of cobalt ferrite, magnetite, and magnesium ferrite, Opt. Mater. (Amst). 91 (2019) 279-285.

doi:10.1016/j.optmat.2019.03.031.

[26] S. V. Spirou, S.A. Costa Lima, P. Bouziotis, S. Vranješ-Djurić, E.K. Efthimiadou, A. Laurenzana, A.I. Barbosa, I. Garcia-Alonso, C. Jones, D. Jankovic, O.L. Gobbo, Recommendations for in vitro and in vivo testing of magnetic nanoparticle hyperthermia combined with radiation therapy, Nanomaterials. 8 (2018). doi:10.3390/nano8050306.

\section{Figures}




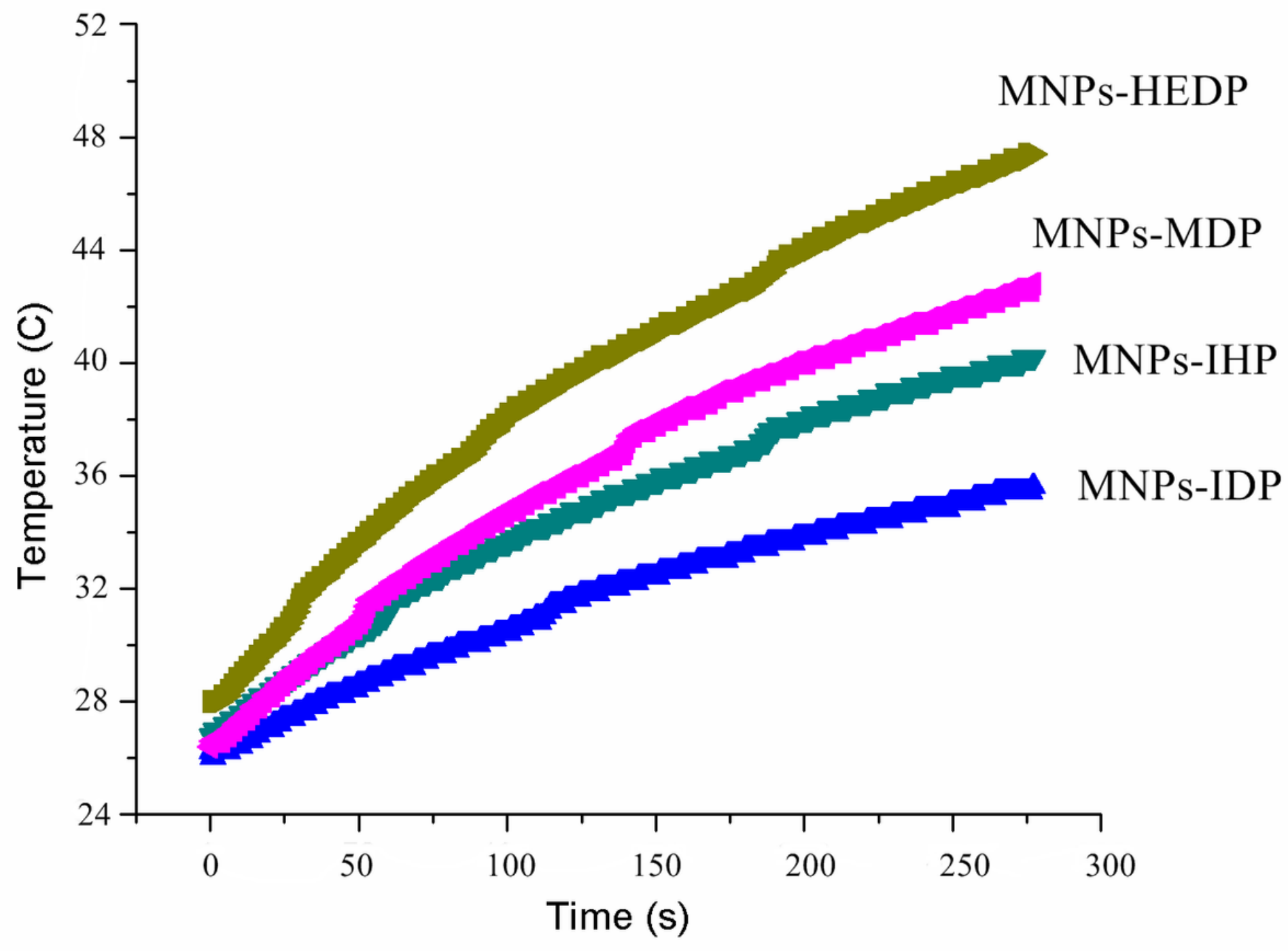

Figure 1

Heating capacity of Fe304-MPD, Fe304-HEDP, Fe304-IDP, and Fe304-IHP MNPs at $30 \mathrm{mT}$ and $397 \mathrm{kHz}$ 


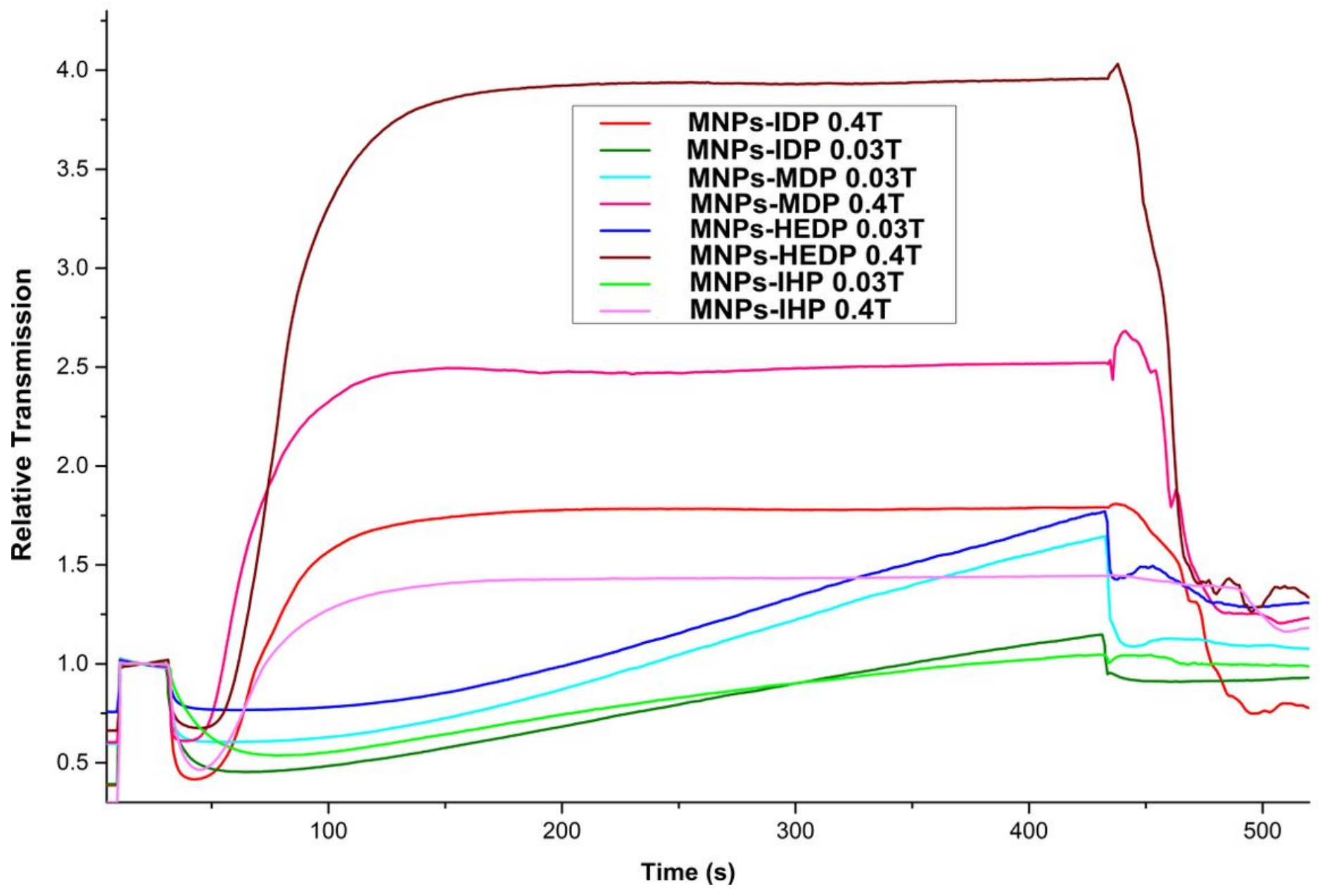

Figure 2

Time dependence of transmitted diode laser light $(\lambda=655 \mathrm{~nm})$ for investigated MNPs at magnetic field strengths of $30 \mathrm{mT}$ and $400 \mathrm{mT}$. 


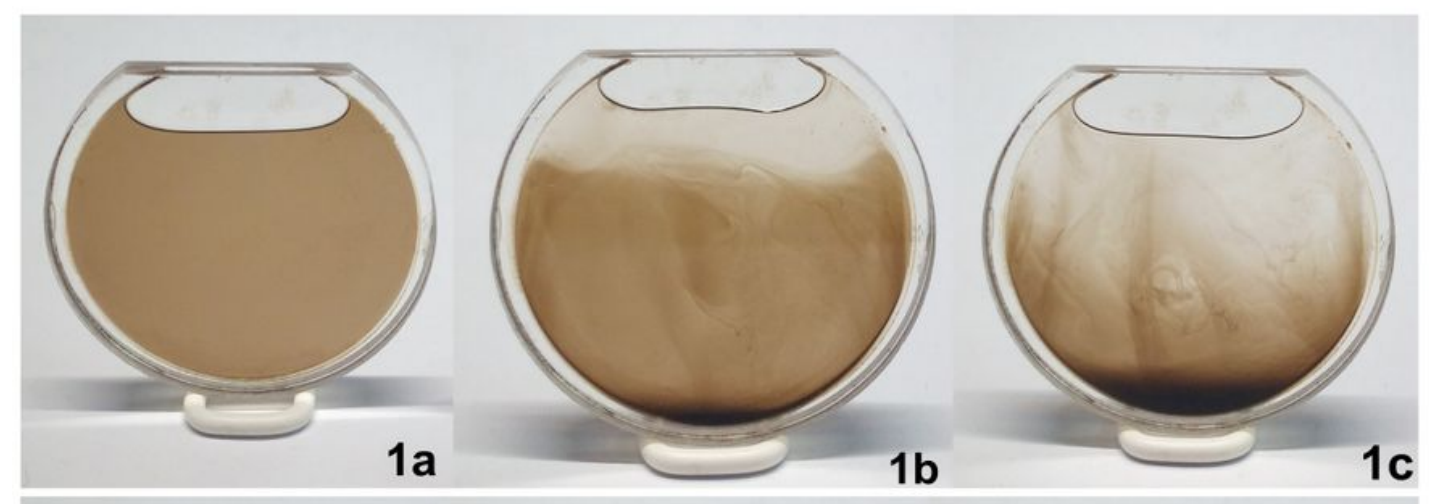

\section{MNPs-MDP}

\section{MNPs-HEDP}

\section{MNPs-IDP}

\section{MNPs-IHP}

\section{Figure 3}

Fe304-MPD MNPs (1a, 1b, 1c), Fe304-HEDP MNPs (2a, 2b, 2c), Fe304-IDP MNPs (3a, 3b, 3c), and Fe304IHP MNPs (4a, 4b, 4c) precipitate formed in non-alternating magnetic field 


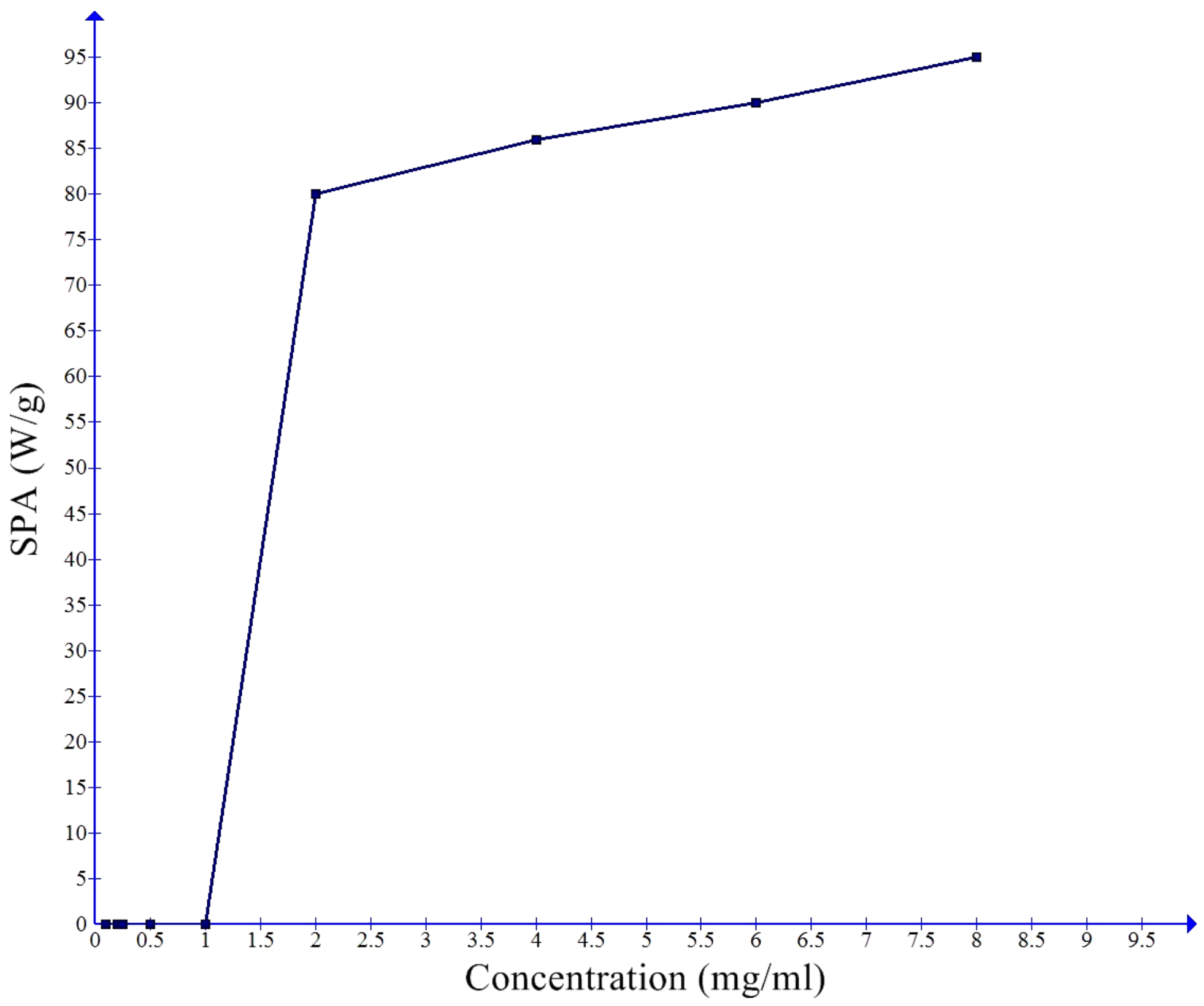

Figure 4

SPA values of Fe304-HEDP MNPs at different concentrations $(397 \mathrm{kHz}, 30 \mathrm{mT})$ 


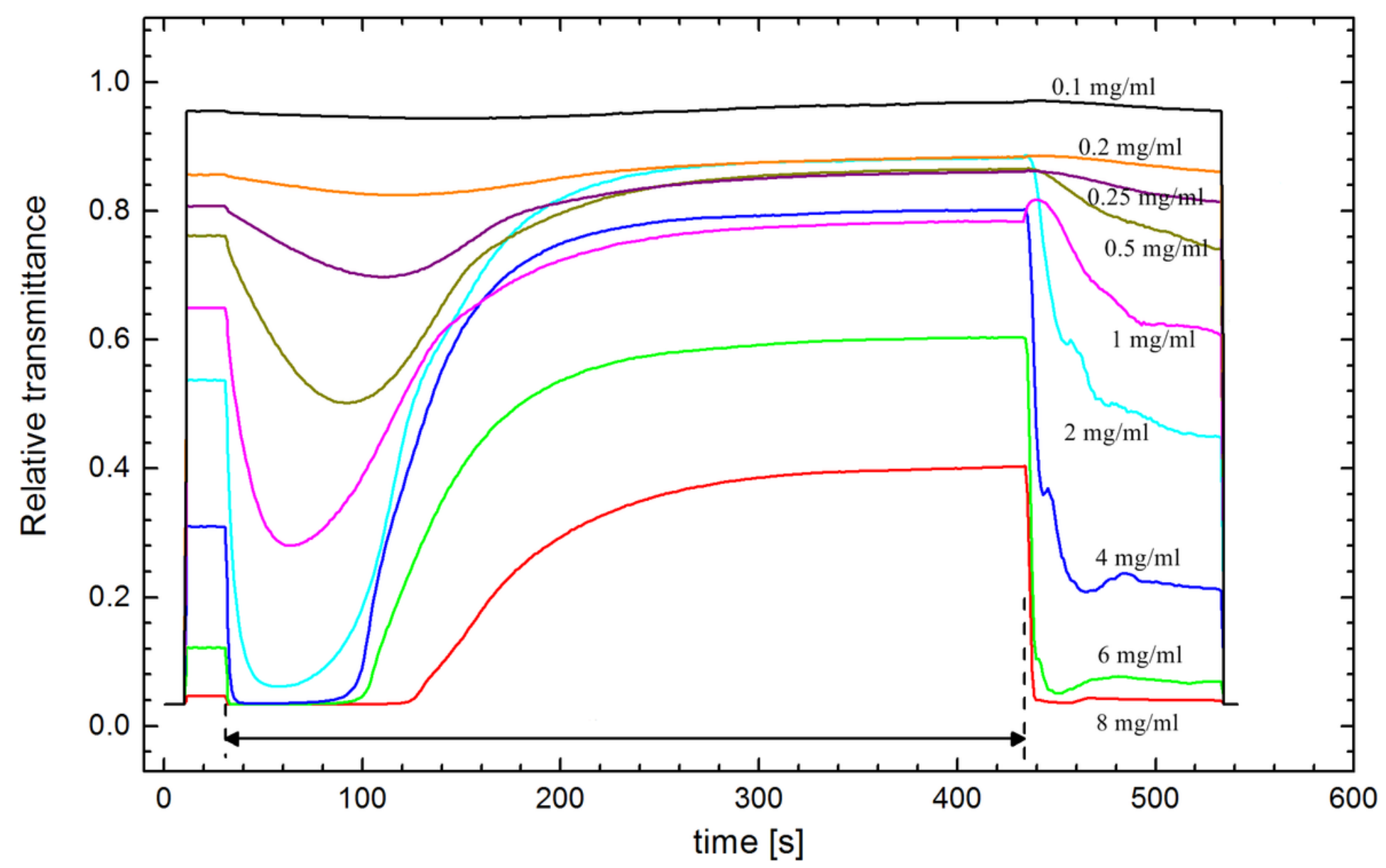

Figure 5

Time dependence of transmitted diode laser light $(\lambda=655 \mathrm{~nm})$ for different concentrations of the Fe304HEDP MNPs at magnetic field strength of $400 \mathrm{mT}$.

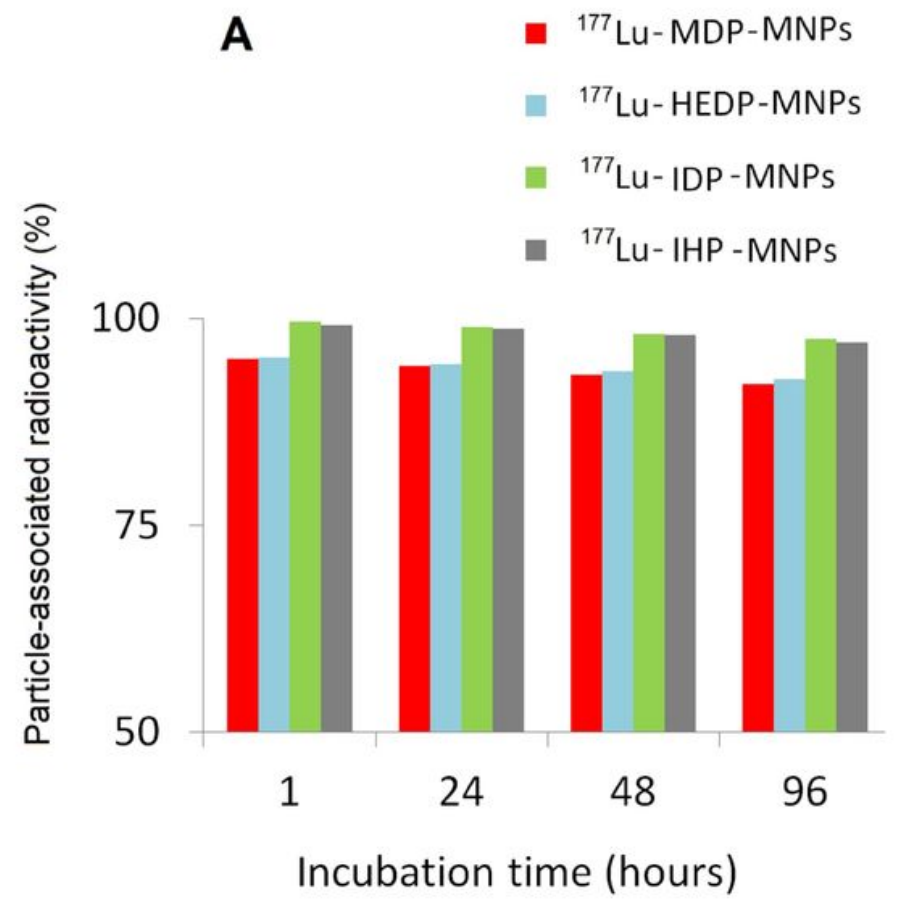


Figure 6

In vitro stability of 177Lu-MDP-MNPs, 177Lu-HEDP-MNPs, 177Lu-IDP-MNPs, and 177Lu-IHP-MNPs in A) saline and B) human serum after incubation at $37^{\circ} \mathrm{C}$ over $96 \mathrm{~h}$ 